\title{
All-optical Signal Processing Devices for Photonic Networks: Towards Packet Switching
}

\author{
Hans-Peter Nolting \\ Heinrich-Hertz Institut für Nachrichtentechnik, Berlin GmBH, 10587 Berlin, \\ Einsteinufer 35, \\ tel: +4930 31002 427,fax: +49 3031002 241, nolting@hhi.de
}

\begin{abstract}
Key words: All-optical, signal processing devices, photonic networks, signal processing methods, terabit systems, terabit router, packet switching, OTDM-Systems,
\end{abstract}

\section{INTRODUCTION}

The future internet demands for increase of the transmission capacity in access and core networks. Today telecom operators are installing massively WDM links to gratify the demand for capacity upgrades mainly for point-topoint connections. The link capacity will grow to a few Tbit/s per fiber. It is expected that optical time domain techniques (OTDM) will be used to increase the bit rate per WDM channel further beyond the highest available electronic processing speed. Today $10 \mathrm{Gbit} / \mathrm{s}$-systems are commercial available, for the next months $40 \mathrm{Gbit} / \mathrm{s}$ systems are announced. With today's OTDM techniques an increase to $160 \mathrm{Gbit} / \mathrm{s}$ is feasible. It is expected that the bit rate for one wavelength channel may be increased to about $1 \mathrm{Tbit} / \mathrm{s}$. The needs for the pulse sources, the demultiplexers, and the design of the fiber system will be discussed.

Today the optical networks are composed of point-to-point links with electronical switching and routing functions in the network nodes (SDH-, 
ATM-hierarchy). The evolution of the network will go to more advanced nodes, where the signal will stay in the optical domain and will be switched, routed and processed by all-optical signal processing methods. For complex processing functions a hybrid solution may be advantageous, where extensive calculations will be done in the electrical domain using the superior performance of modern CPUs. But for some selected functions like all-optical high-speed switching (up to $100 \mathrm{Gbit} / \mathrm{s}$ today), wavelength conversion and 3R-regeneration (up to $40 \mathrm{Gbit} / \mathrm{s}$ today) all-optical signal processing devices are investigated in system experiments and have shown their merits. These components are thought to be suitable for "moderate" bit rates like 10 to $40 \mathrm{Gbit} / \mathrm{s}$ system due to their performance in term of simplicity, advanced functionality, cost and reliability. The state of the art of these all-optical signal processing devices will be described and further evolution will be discussed.

Today monitoring and control of the network is done by the electronics (SDH, ATM). If the signal stays in the optical domain, for operation, control and maintenance new methods have to be developed based on optical signal processing methods. Optical sampling can be used for monitoring purpose of optical signals at very high bit rates. First results will be discussed.

The future internet will force a change from circuit switched networks to packet switched networks. If we use OTDM systems, than the well known bit-interleaving technique for the multiplexing / demultiplexing can not be used any more. Packets arriving at a lower bit rate at the node have to be compressed in time and bit shape and decompressed at the other end. Here some modelling results shall show the main problems to overcome. To reduce the processing time of the packet at a node the concept of "switching on the flight" will be studied. Assuming IP with label switching, the label has to be separated from the packet, read, analysed, a new label computed, the routing performed and the new label written to the packet. The label separation and label adding function will be done with all-optical processing functions. The packet itself should stay in the optical domain. For this a fiber memory with a 3R-regenerating function will be used. The label will be processed - in a first step - with a high-speed electronic unit.

Optical signal processing will play a key role in this scenario. In particular packet switching at ultra-high speed is a challenge. State of the art of optical signal processing in the bit rate range from 10 to $160 \mathrm{Gbit} / \mathrm{s}$ and an outlook into the future will be given, where bit rates of about $1 \mathrm{Tbit} / \mathrm{s}$ are announced. 


\section{OTDM-TRANSMISSION SYSTEMS}

In Optical Time Division Multiplexing (OTDM) systems the multiplexing from a "low bit rate" (today $10 \mathrm{Gbit} / \mathrm{s}$ ) is done by distributing short pulses from a ps-pulse source to a variety of $n$ modulators (each working at $10 \mathrm{Gbit} / \mathrm{s}$ ) and combining the individual delayed pulses to an interleaved bit stream of $\mathrm{n} * 10 \mathrm{Gbit} / \mathrm{s}$, as is shown in the figure.
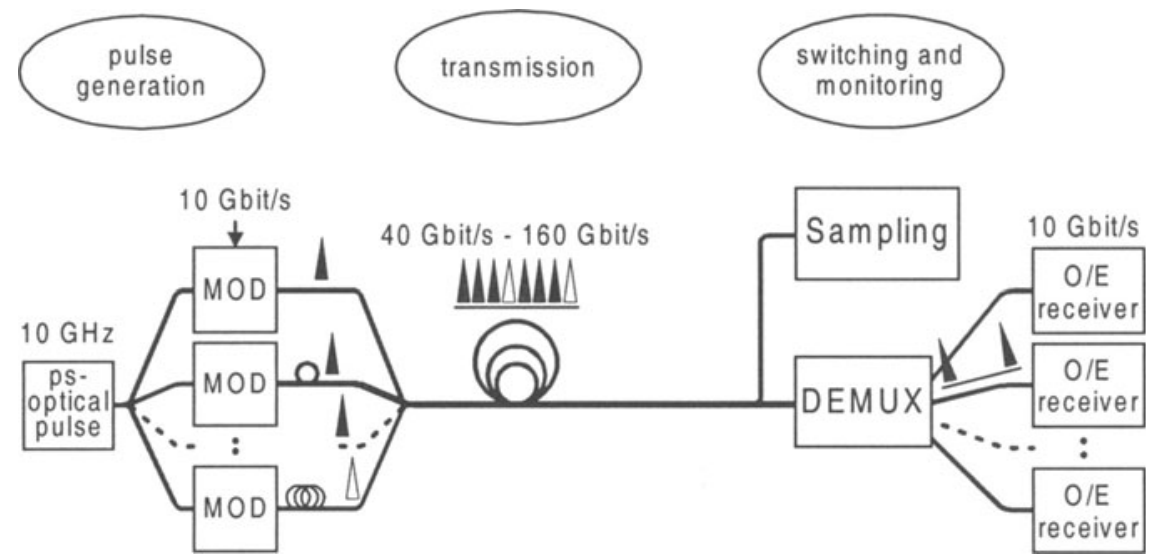

The critical device is the ps-pulse source. For the transmission of short pulses on standard fiber special care has to be taken, like dispersion management and / or polarisation mode dispersion compensation (PMD). Demultiplexen needs an all-optical switch, working with a switching window of the pulse width, but with a repetition rate of the basic bit rate. In order to switch at the right time slot, an optical clock recovery circuit gives the time information.

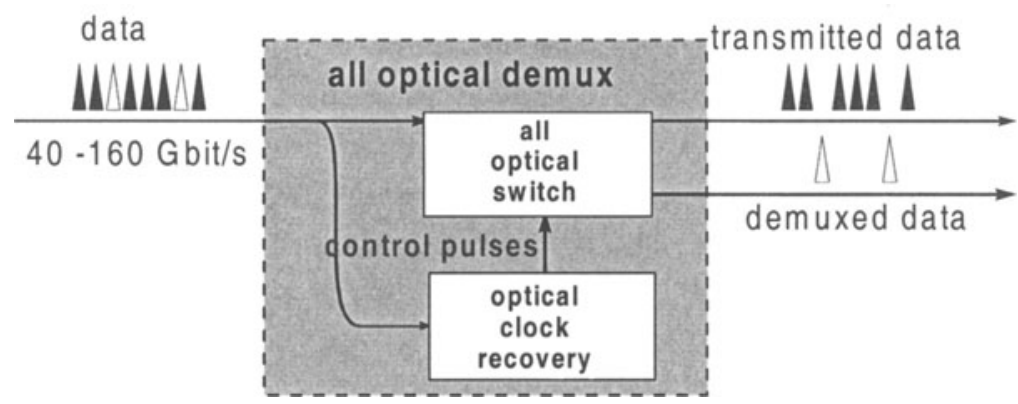




\subsection{Pulse Source}

For ultra-high speed transmission fs-pulses are necessary. One way to generate sub-pico second pulses is the so-called tunable mode locked laser (TMLL) ${ }^{1}$. Here a schematic of the pulse train is shown, summarising all important parameters of the TMLL in this plot $^{2}$.

\section{Summary of TMLL Characteristics}

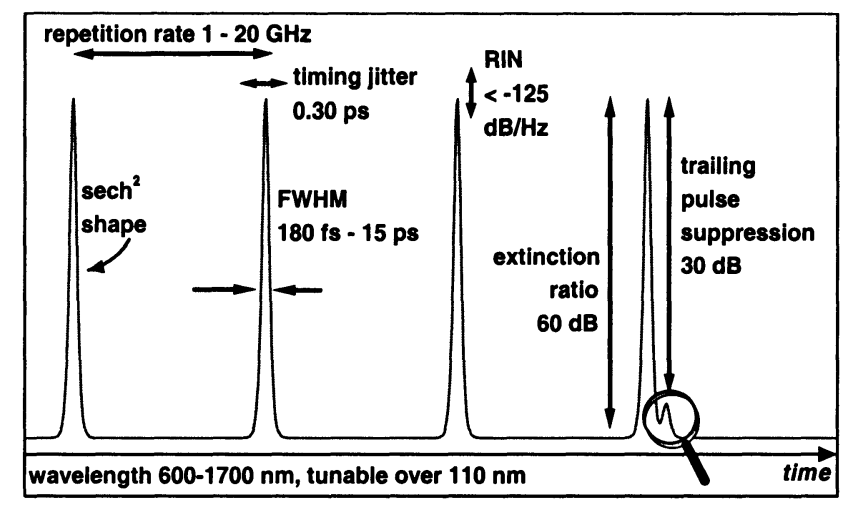

Mode-locking : passively, hybrid electrically, hybrid optically

7-8 Februar 2000

ONDW 2000, Athen

H.P. Noting. HHI, Berlin

- The repetition rate of the TMLL can be tuned form 1 to $20 \mathrm{GHz}$ by varying the cavity length.

- The pulses have a sech^2 shape for pulse widths down to $600 \mathrm{fs}$.

- The pulse width can be tuned from 180 fs to 15 ps by changing the grating and by switching from collimated to focussed projection onto the grating.

- The RMS timing jitter of the pulses is typically about $300 \mathrm{fs}$.

- The relative intensity noise is smaller than $-125 \mathrm{~dB}$ per $\mathrm{Hz}$.

- The extinction ratio is about $60 \mathrm{~dB}$ and the trailing pulse suppression is about $30 \mathrm{~dB}$.

And finally, the centre wavelength can in principal be anywhere between 600 and $1700 \mathrm{~nm}$ depending on the type of laser diode used. The tuning range for a fixed diode is as large as $110 \mathrm{~nm}$.

The saturable absorber is created by nitrogen ion implantation through one facet of the fabry perot laser diode.

Mode locking can be achieved passively, hybrid electrically and hybrid optically. 
There is a variety of applications for ps-pulse sources in OTDM systems: (i) as transmitter, (ii) as clock recovery in 3R-regeneration (re-shaping, retiming), (iii) synchronisation in demux and (iv) optical sampling.

Thus the ps-pulse source is the key device for OTDM-systems. The shortness of the pulses and the spectral purity determine the transmission capacity and the transmission length.

\subsection{Dispersion Management}

The propagation of pulses on fibers is limited by fiber loss, fiber dispersion, non-linearity and other effects. The invention of the Erbiumdoped fiber amplifier (EDFA) has overcome the loss limit by periodic signal amplification on a long fiber link. The transmission of short pulses on standard fibers (SMF with a dispersion of $17 \mathrm{ps} / \mathrm{km} / \mathrm{nm}$ ) leads to a broadening of the pulse width, which also limits the transmission length. The transmission length can be increased by compensating the accumulated dispersion by adding some fiber length with a negative dispersion (DCF fiber). For applications with very short pulses (terabit systems), which have a broad wavelength spectrum, or for WDM applications the accumulated dispersion has to be compensated in a wide wavelength region. In this case the dispersion compensating fibers have to compensate the dispersion itself and higher order dispersion.

The maximum propagation distance ${ }^{3}$ of a transmission line composed of cascaded links of SMF, EDFA and compensating fiber is a function of the input power of the signal, as is shown in the figure. For low input power the limiting factor is the noise accumulation generated by the optical amplifier. For large input power the limiting factor is the combined influence of non linear effects.

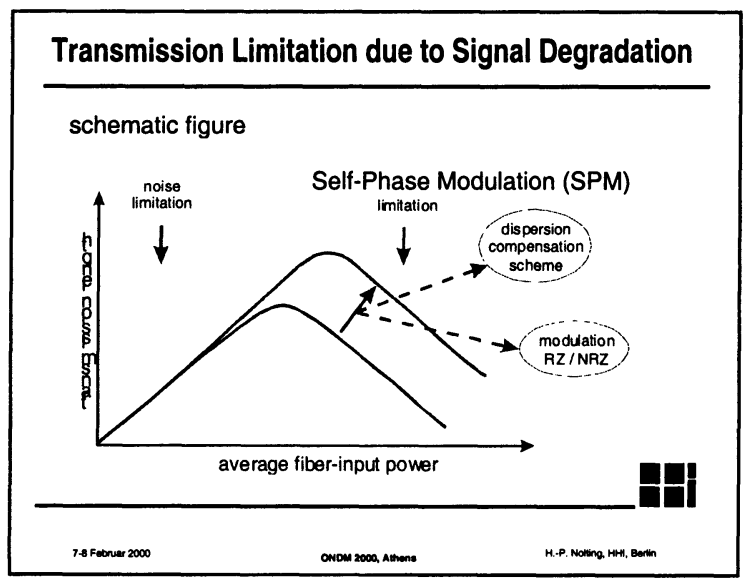




\subsubsection{Terabit System Design}

Modelling results on tera bit transmission systems are not available at this time. Some basic trends can be deduced from fundamental work at lower bit rates. In the first example experimental and simulation results are compared for transmission on dispersion compensated standard fiber links, while the two next are only theoretical studies of dispersion shifted fiber links at higher bit rates.

Recently four WDM-channels, each carrying a data rate of 40Gbit/s were transmitted over a $100 \mathrm{~km}$ single mode fiber (SMF) link in RZ format ${ }^{4}$. The fiber link consisted of a 100km SMF span with an EDFA and a dispersion compensating fiber (DCF). The experiment was numerically simulated and the calculated results were in good agreement with experiment.

For the $4 \times 40 \mathrm{Gbit} / \mathrm{s}$ experiment a DCF (labeled as DCF1) is used for which second order dispersion $\mathrm{D}$ is fully compensated but not the third order dispersion $\mathrm{S}$. The results of the calculations depicted in the figure show

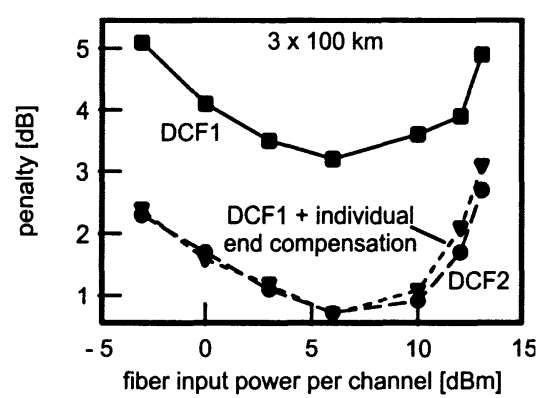
that for such a compensation only up to three spans can be cascaded. If, however, DCF2 is used which compensates both $\mathrm{D}$ and $\mathrm{S}$ the penalty curve has the same shape but is $3 \mathrm{~dB}$ lower. A similar curve results if dispersion is compensated in the receiver, e. g. by a fiber Bragg grating.

Next the numerically investigation of the cases of $8 \times 40 \mathrm{Gbit} / \mathrm{s}, 8 \times 80 \mathrm{Gbit} / \mathrm{s}$ and $8 \times 160 \mathrm{Gbit} / \mathrm{s}$ transmission over $5 \times 100 \mathrm{~km}$ of SMF and $100 \mathrm{~km}$ amplifier spacing are shown. In order to compare the results with the $4 \times 40 \mathrm{Gbit} / \mathrm{s}$ experiment pulse widths of $4 \mathrm{ps}, 2 \mathrm{ps}$

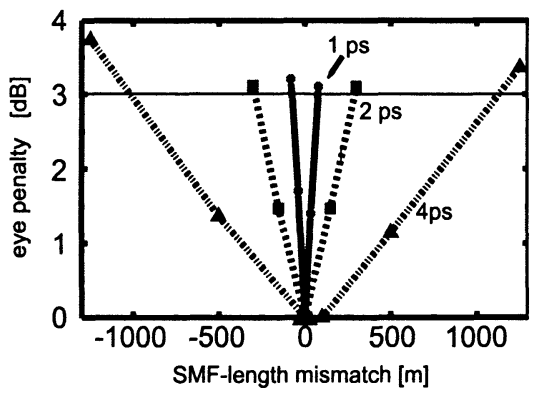
and $1 \mathrm{ps}$ and channel spacings of $2 \mathrm{~nm}$, $4 \mathrm{~nm}$ and $8 \mathrm{~nm}$ are taken for $40 \mathrm{Gbit} / \mathrm{s}$, $80 \mathrm{Gbit} / \mathrm{s}$ and $160 \mathrm{Gbit} / \mathrm{s}$, respectively. Each span is assumed to be completely compensated by DCF2. An important result of the calculation is that four-wave mixing and cross phase modulation effects are negligible for the dispersion map and channel spacings considered.

Further an evaluation of the stability of transmission with respect to small changes in the degree of dispersion compensation has been done, by deviating the SMF length from the value of complete compensation. The SMF-length tolerance is due to the increased broadening of the pulses for deviation of total dispersion from zero. The results of the calculations are 
shown in the figure. The optimum input power is $10 \mathrm{dBm}$ per channel. In this figure the eye closure penalty for deviations from the ideal fiber length is depicted. In order to keep transmission penalty below the $3 \mathrm{~dB}$ penalty an SMF length tolerance range of $1.1 \mathrm{~km}, 0.28 \mathrm{~km}$ and $0.07 \mathrm{~km}$ is necessary for the $4 \mathrm{ps}, 2 \mathrm{ps}$ and $1 \mathrm{ps}$ pulse width, respectively. Length tolerances well below $1 \mathrm{~km}$ are difficult to realize and a way must be found to increase the numbers listed above. Since for non-soliton transmission pulse broadening by dispersion depends inversely on the square of the pulse width the above length tolerance are increased by a factor of 4 if pulse widths of $8 \mathrm{ps}, 4 \mathrm{ps}$ and $2 \mathrm{ps}$ are used for $40 \mathrm{Gbit} / \mathrm{s}, 80 \mathrm{Gbit} / \mathrm{s}$ and $160 \mathrm{Gbit} / \mathrm{s}$, respectively.

Kazuro Kikuchi ${ }^{5}$ has discussed the design of an ultra-high speed optical transmission system based on a dispersion-shifted fiber. It is shown that the distance for dispersion compensation / amplifier section is decreasing for increasing bit rate.

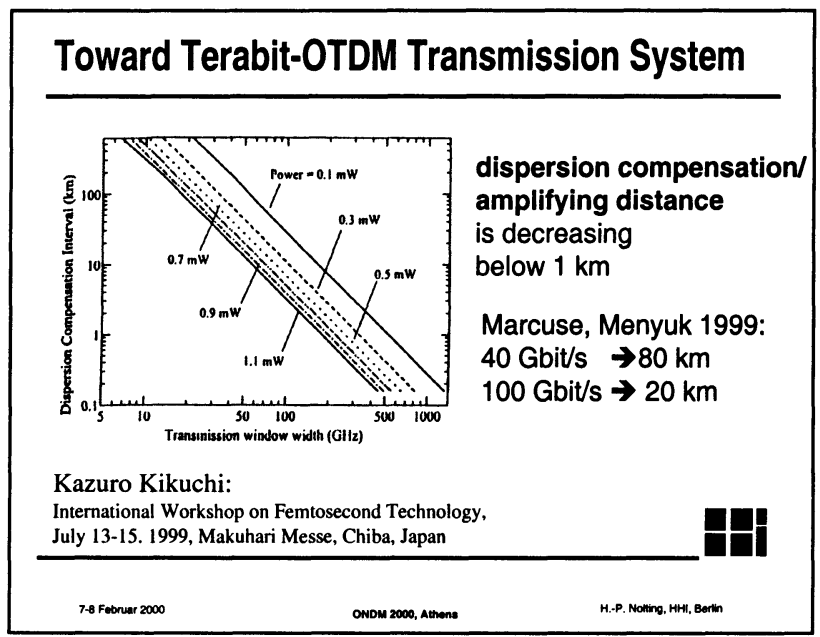

Marcuse and Menyuk have investigated theoretically the tolerances of a $100 \mathrm{Gbit} / \mathrm{s}$ transmission system for three different formats: non return to zero (NRZ), return to zero (RZ) and the dispersion-managed soliton (DMS) propagation. It is shown, that the amplifier span has to be reduced to $20 \mathrm{~km}$ compared to $80 \mathrm{~km}$ for $40 \mathrm{Gbit} / \mathrm{s}$ systems. Further the tolerances for power and dispersion variations are shown to decrease with increasing transmission length and bit rate. These results are in agreement with the experimental and theoretical results from $\mathrm{HHI}$, given above. 


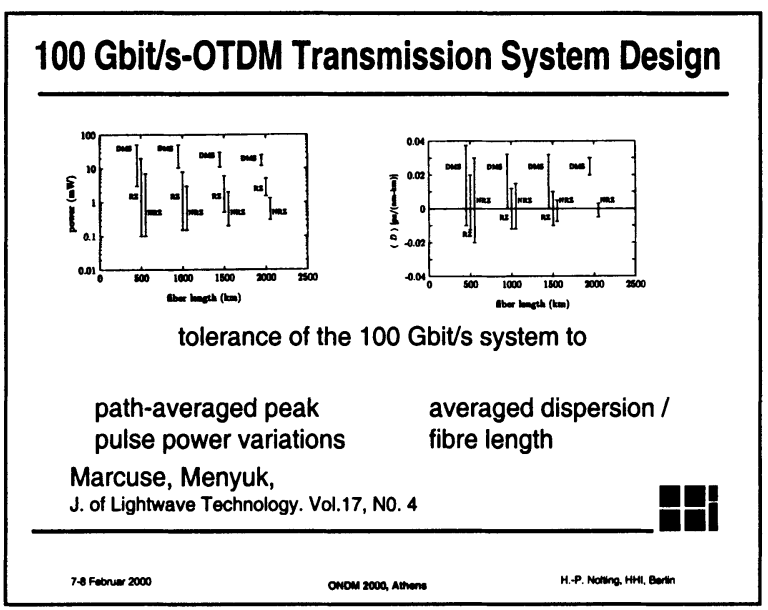

From this we can learn that the tolerances of the operation windows will become even more tight, if we go from $160 \mathrm{Gbit} / \mathrm{s}$ to much higher values like $1000 \mathrm{Gbit} / \mathrm{s}$. It looks like that the development of new fibers and new dispersion management concepts are necessary.

\subsection{System Experiments}

Some of the actual hero system experiments, aiming for highest transmission capacity on a single fiber, are shown in the table:

\begin{tabular}{|c|c|c|c|c|}
\hline laboratory & WDM & OTDM & $\begin{array}{l}\text { basic bit } \\
\text { rate } \\
\text { (electronic) }\end{array}$ & $\begin{array}{l}\text { capacity } \\
\text { [Gbit/s] }\end{array}$ \\
\hline $\begin{array}{l}\mathrm{HHI}^{6}, \quad \text { no } \\
\text { transmission }\end{array}$ & 8 & 8 & 10 & 640 \\
\hline Siemens $^{7}$ & 80 & 1 & 40 & 3200 \\
\hline Lucent/BT $^{8}$ & 1 & $8 / 16$ & $20 / 10$ & 160 \\
\hline NTT $^{9}$ & 19 & 16 & 10 & 3040 \\
\hline
\end{tabular}

At HHI fundamental investigations concerning the data format, the method of dispersion compensation, the amplifier span and other parameter are investigated and the results are shown in the following table. 


\begin{tabular}{|c|c|c|c|}
\hline & year & $\begin{array}{c}\text { capacity } \\
\text { [Gbit/s }\end{array}$ & \multicolumn{1}{|c|}{ description } \\
\hline $\mathrm{HHI}^{10}$ & 1997 & 40 & $\begin{array}{c}150 \mathrm{~km} \mathrm{single} \mathrm{span} \\
\text { comparison of post- and } \\
\text { precompensation comparison } \\
\text { with TWF and DSF }\end{array}$ \\
\hline $\mathrm{HHI}^{11}$ & 1998 & 40 & $\begin{array}{l}430 \mathrm{~km} \mathrm{4} \text { spans mid-span } \\
\text { spectral inversion }\end{array}$ \\
\hline $\mathrm{HH}^{12}$ & 1998 & $4 \times 40$ & $100 \mathrm{~km}$ single span \\
\hline $\mathrm{HH}^{13}$ & 1999 & 40 & $\begin{array}{c}430 \mathrm{~km} \mathrm{4} \text { spans comparison } \\
\text { of } \mathrm{RZ} \text { and NRZ modulation } \\
\text { format }\end{array}$ \\
\hline $\mathrm{HH}^{14}$ & 1999 & 80 & $\begin{array}{l}106 \mathrm{~km} \mathrm{2} \mathrm{spans} \mathrm{mid-span} \\
\text { spectral inversion }\end{array}$ \\
\hline
\end{tabular}

\subsection{Optical sampling for monitoring of signals}

Network operators need information on the status of their network elements to have control over their network. For a variety of applications it is necessary to guarantee the quality of the service (QoS). One important parameter of a transmission line is the bit error rate (BER) of the link. In an OTDM-system the basic bit rate (electronic) is lower than the (optical) bit rate on the fiber. Therefore optical methods for measuring are necessary.

Optical sampling ${ }^{15}$ can provide some insight in the shape of the signals and we hope to extend such a measurement setup to investigate the Q-factor of the system, which is correlated with the BER curves.

The principle of optical sampling ${ }^{16}$ is shown in the figure. For a periodic signal it is possible to select information on the height of the amplitudes on a repetition rate, which is much lower than the bit rate of the signals.

To get a measure for the amplitude of the signal at a time a logical AND function has to be used between very short pulses as a control signal and the data. 


\section{Principle of Optical Sampling}

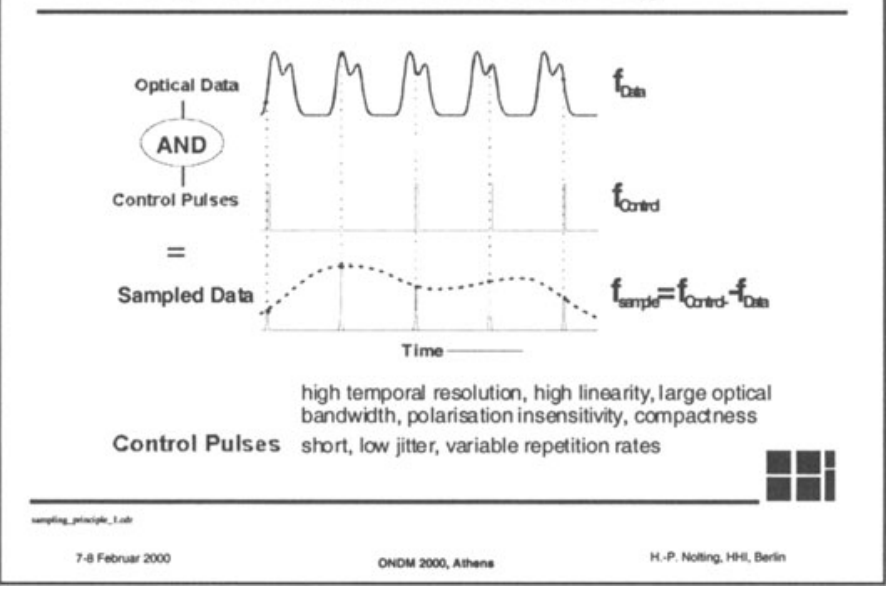

For this purpose the four wave mixing process in the gain-transparent switch between control and signal can be used, which generates a new signal that is proportional to the desired amplitude and can be filtered out.

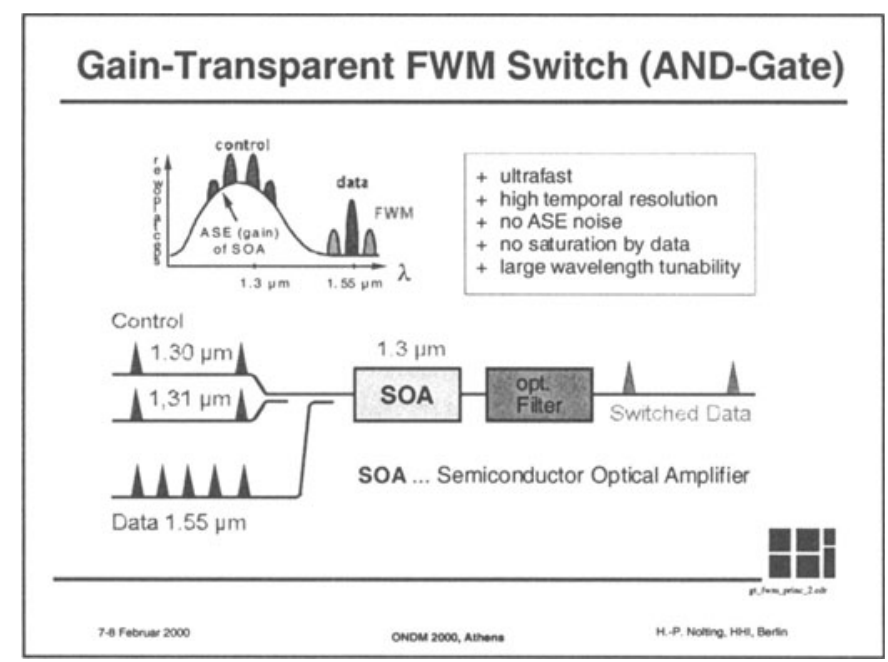

As is shown in the figure, two pumps around the wavelength $1,3 \mu \mathrm{m}$ as control are necessary. The control pulses have to be as short as possible, a low jitter and the repetition rate has to be variable. The switch needs a high linearity, high temporal resolution, large optical bandwidth and polarisation insensitivity. This is fulfilled by the gain-transparent switch.

As first example the shape of a $160 \mathrm{Gbit} / \mathrm{s}$ optical sampled data stream ${ }^{16}$ is shown in the figure. This can not be done with pure electronic methods. 


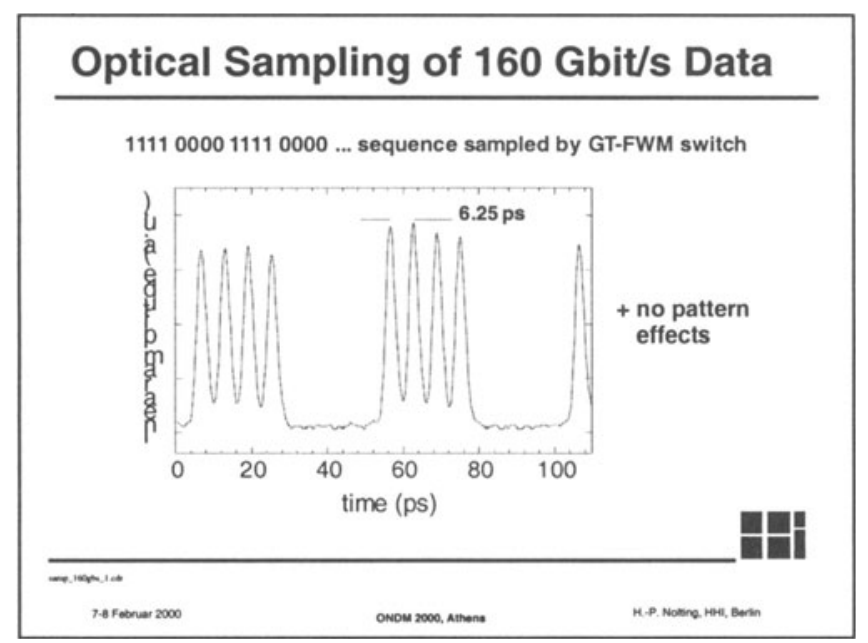

\section{BASIC OPTICAL SIGNAL PROCESSING DEVICES}

We use two lines of basic optical signal processing devices, both are based on semiconductor laser (amplifier) material. The advantages of this choice are (i) short device length (compared to fiber), (ii) robust and stable operation for integrated devices, (iii) cheap to fabricate and they offer (iv) gain .

For all-optical switching non coherent effects are used. Thus for data input and control input we need always two different wavelengths.

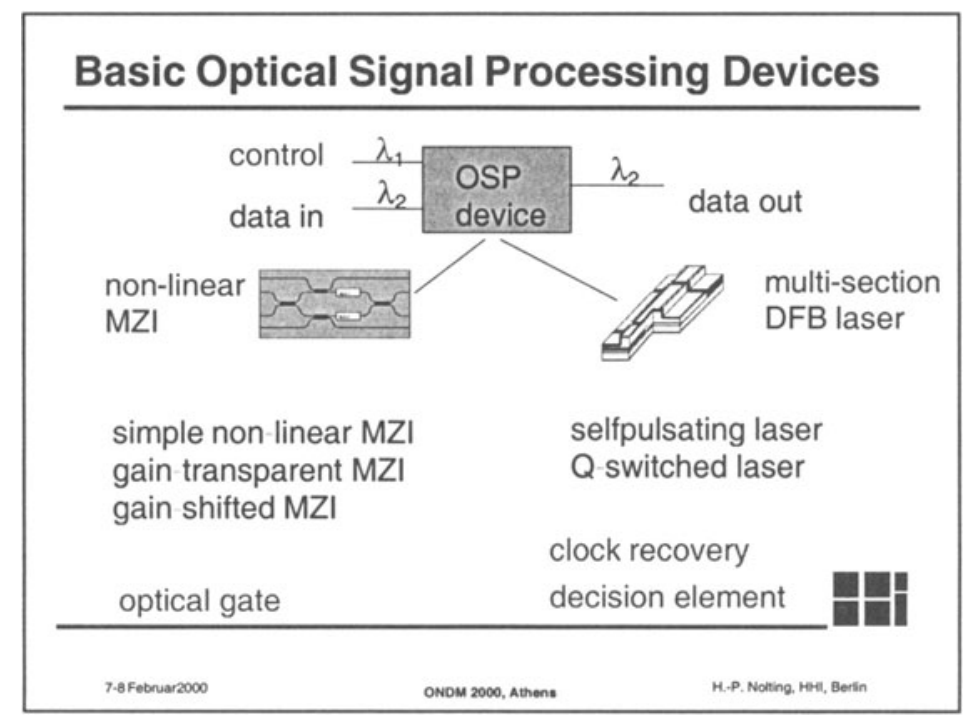


As optical gate the non-linear Mach-Zehnder Interferometer (MZI) with semiconductor optical amplifier (SOA) is used. The switching behaviour can be shaped by using different band gap material for the SOA (simple nonlinear MZI, gain-transparent MZI, gain-shifted MZI). This component as a single pass device has a very high speed potential compared to laser devices, which are multi-pass elements.

For clock recovery a multi-section DFB laser operating as a selfpulsating laser can be used. By introducing data to the free running laser, the output signal can be locked to the incoming data stream. Basically the same device, but optimised for switching behaviour can be used as a decision element.

\section{3R-REGENERATION}

Data transmitted over large distances show signal degradation due to the fiber non-linearities and dispersion effects. The passing of a network node in the optical domain will add further noise and crosstalk accumulation due to switching and wavelength conversion in the node. All-optical $3 \mathrm{R}$ signal regeneration (ㅌe-amplification, $\underline{\mathbf{R}}$-timing, $\underline{\mathbf{R}}$-shaping) is a key function needed for scalable all-optical networks. The main functional blocks are the optical clock recovery and the decision element.

\section{All-Optical 3R Signal Regeneration}

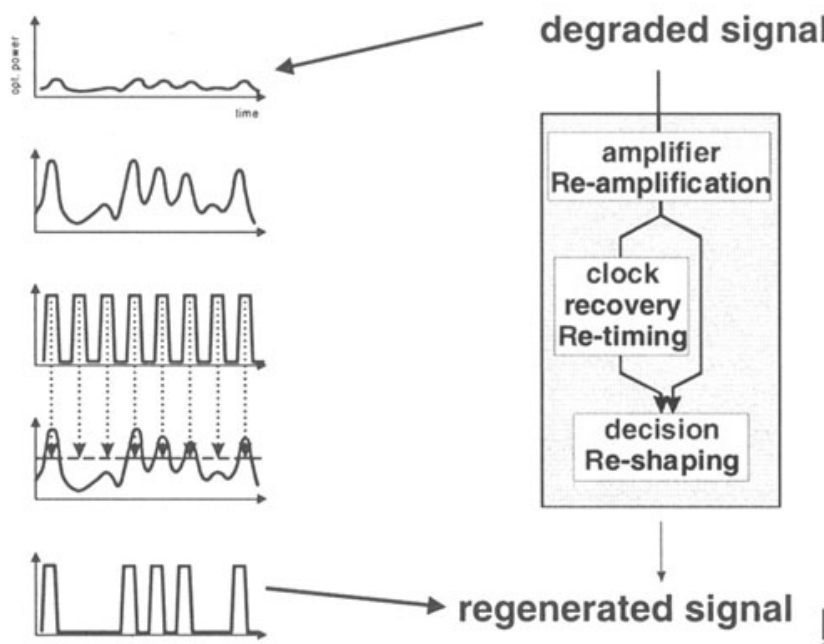




\subsection{Non-linear Mach-Zehnder Interferometer as basic all-optical Switch}

Interferometric switches incorporating semiconductor optical amplifiers (SOAs) have been widely investigated for high-speed all-optical signal processing. In these switches, an optical control signal depletes the carriers in the SOAs. The carrier depletion causes a gain change in the SOA which is accompanied by a change of refractive index. The latter leads to a phase change of the data signal and is used for interferometric switching. The wavelength of the control signal (blue) and the input signal (red) have to be different to avoid coherent effects.

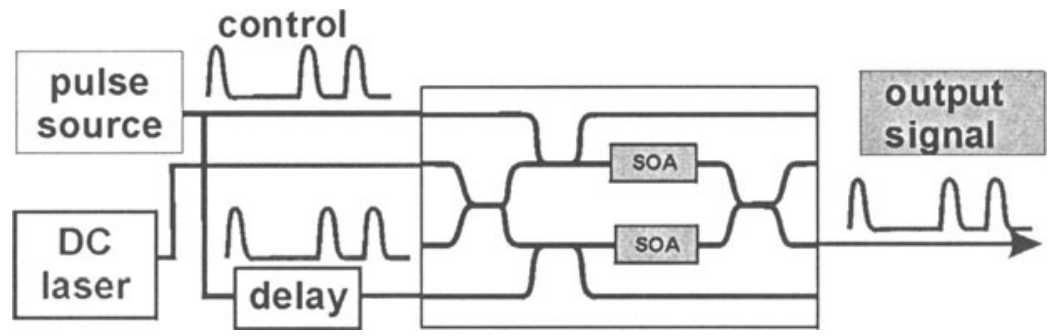

The device can be used for different applications:

- as wavelength converter with a constant amplitude of the input light

- as optical gate to led pass optical signals (red) on the input port to the output port (not shown in figure)

- in combination with a clocked signal this gate can be used as switch for a 3R-regenerator

We prefer an interferometer with two control inputs, to use push-pull operation with a short delay between both control signals (blue). This architecture can operate at higher speed than the single control interferometer.

The MZ-interferometer with long SOAs has a speed potential of about a few $100 \mathrm{Gbit} / \mathrm{s}$.

The switching behaviour can be shaped by using different band gap material for the SOA: 


\section{Switching Schemes}

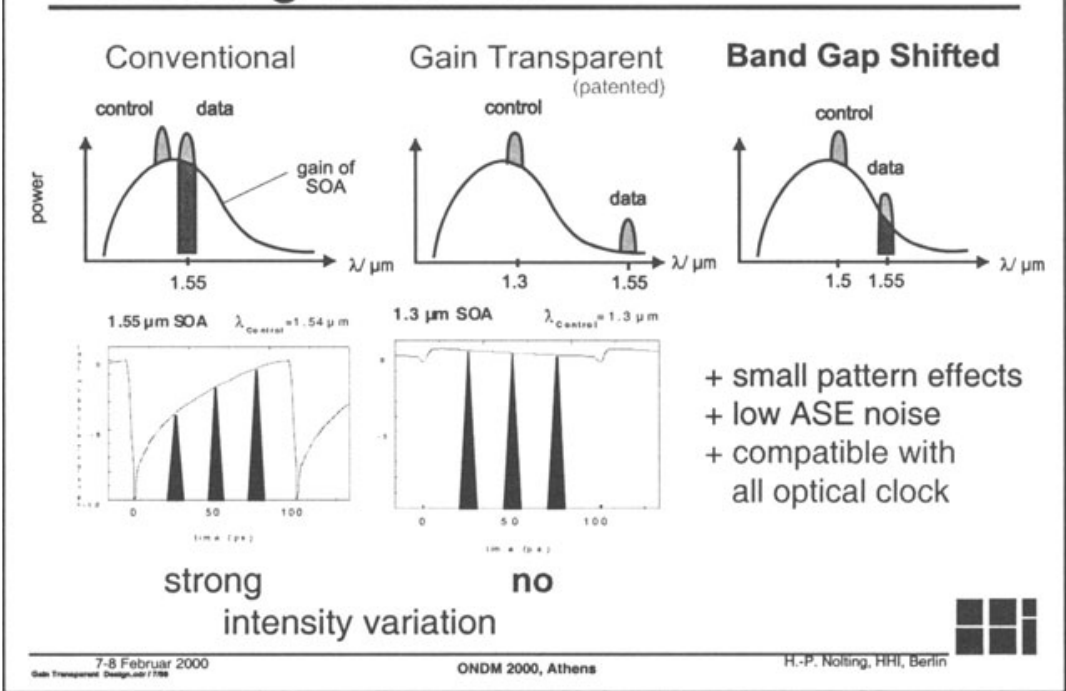

- simple non-linear MZI, ${ }^{17}$ data and control pulses are both in the maximum of the gain curve. The resulting switching characteristic shows a strong pattern effect for the passed signals due to gain saturation effects

- gain-transparent $M Z I^{18}$, only the control pulses are in the gain maximum. The data pulses are far away from the gain maximum and will be switched only by phase changes. The amplitudes of the signal are nearly constant.

- gain-shifted MZI, this is a new concept, where the data wavelength is placed at the border of the gain characteristic. This allows to operate this switch in combination with wavelength converters, which is necessary in some system applications. One example is the 3Rregenerator, where input and output wavelength often have to be identical, but a wavelength conversion is accompanied with a one stage gate function. Here an additional wavelength conversion is necessary.

\subsubsection{Tbit/s demultiplexing with LOTOS}

A new type of very fast switching device has been reported. This switch uses low temperature grown InGaAs/InAlAs ${ }^{19}$ multiple quantum wells in a free space arranged Fabry-Perot resonator. The module achieves a response time of $390 \mathrm{fs}$ with a contrast ratio of 25 in a fiber-based experiment. Using the modules, all-optical demultiplexing is demonstrated for signal pulses 
corresponding to $1.05 \mathrm{Tbit} / \mathrm{s}$, and the demultiplexed optical pulses have been clearly detected.

This ultra-fast switching effect is accompanied with high losses.

\subsection{Selfpulsating Laser as Clock Recovery}

The selfpulsating laser ${ }^{20}$ is a three section DFB laser, which has been developed specially for the clock recovery function. The device has a gain section, a phase shifter section and a Bragg reflector section. Here the

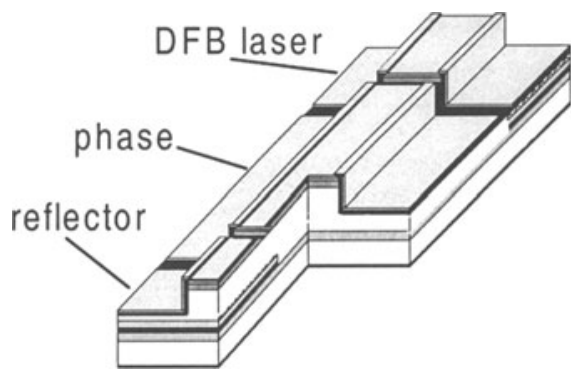
selfpulsation is generated by the feedback from the reflected wave of the Bragg reflector into the gain section under control of the phase section. The device is operated with three DC currents, which control the following functions:

- phase current: selfpulsation on / off

- gain current: tuning of the selfpulsation frequency ${ }^{21}$ with a continuous tuning range from 6 to $40 \mathrm{Gbit} / \mathrm{s}^{22}$

- Bragg current: tuning of the wavelength (a few $\mathrm{nm}$ )

Injection of a data stream (both input wavelengths have to be different, to avoid coherent effects) into the free running selfpulsating laser locks the output signal to the data stream.

\section{Locking of Clock Recovery at $40 \mathrm{~Gb} / \mathrm{s} \mathrm{RZ}$}

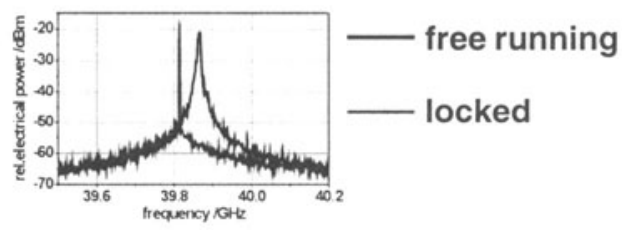

data PRBS $2^{7}-1$
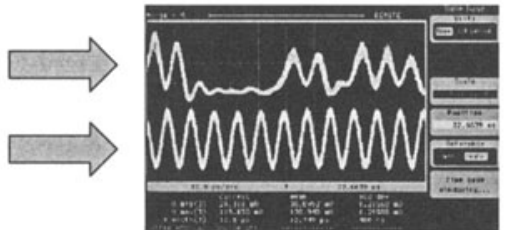

clock

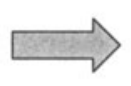




\subsection{Q-switched laser as decision element}

Bistable Q-switching has been demonstrated static and up to $10 \mathrm{Gbit} / \mathrm{s}$ for a specially optimized 3 section DFB laser device, which can be used as a decision element in all-optical signal processing application. This device can easily be integrated monolithically together with the clock recovery circuit. The static switching characteristic is shown.

\section{Bistable Q-Switching for Decision}

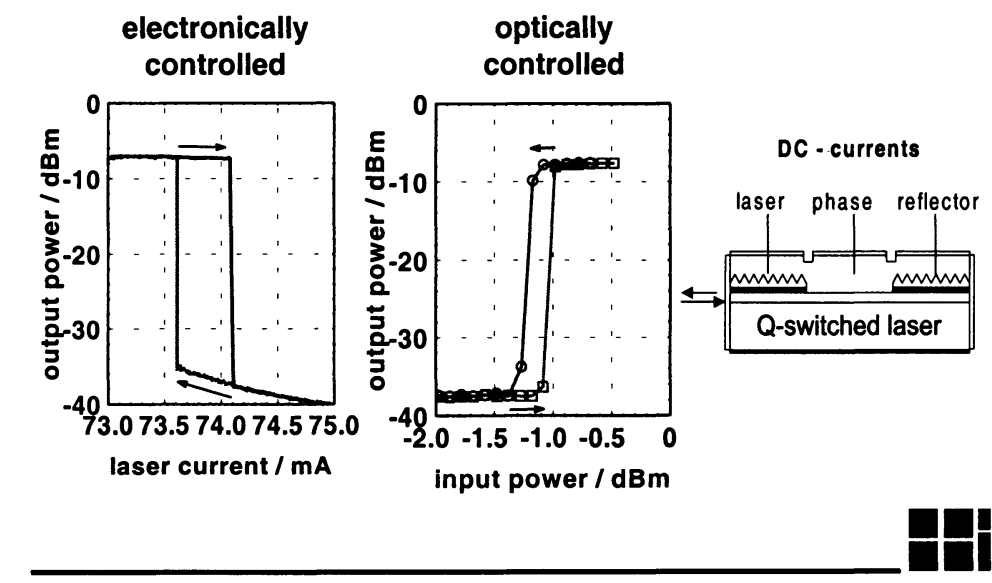

7-8 Februar 2000

ONDM 2000, Athens

H.P. Nolting, HHI, Berlin

\subsection{R-Regenerator System Experiments}

In cooperation of Alcatel and $\mathrm{HHI}$ a $10 \mathrm{Gbit} / \mathrm{s}$ transmission experiment has been successfully conducted with a 3R-regenerator composed of two MZ-interferometers (input wavelength equal to output wavelength) and a selfpulsating laser as clock recovery. The basic setup and the BER measurement curves are shown. 


\section{All-Optical 3R Regenerator in a Loop}

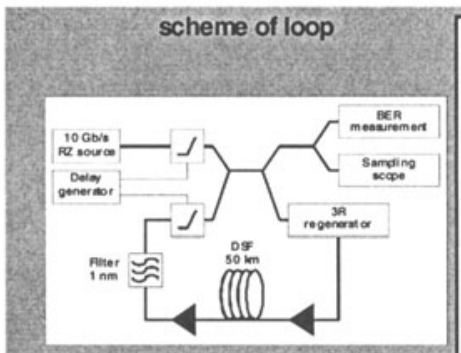

no accumulation of noise or jitter !

$15.000 \mathrm{~km}$ transmission, 300 regenerators cascaded

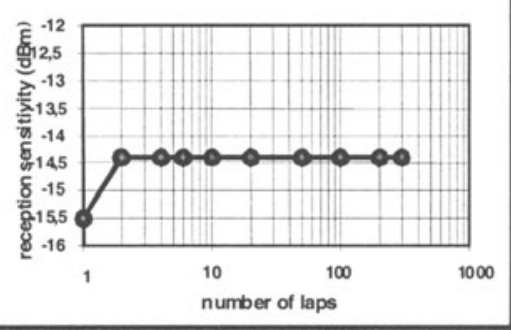

Further on a loop transmission experiment with a repeater length of 50 $\mathrm{km}$ length has been conducted. After the first lap a small penalty of about 1 $\mathrm{dB}$ has been observed. The next 300 laps show no additional penalty, indicating a successfully limiting of noise and jitter accumulation by this all optical 3R-regenerator.

\section{All-Optical 3R-Regenerator / System}

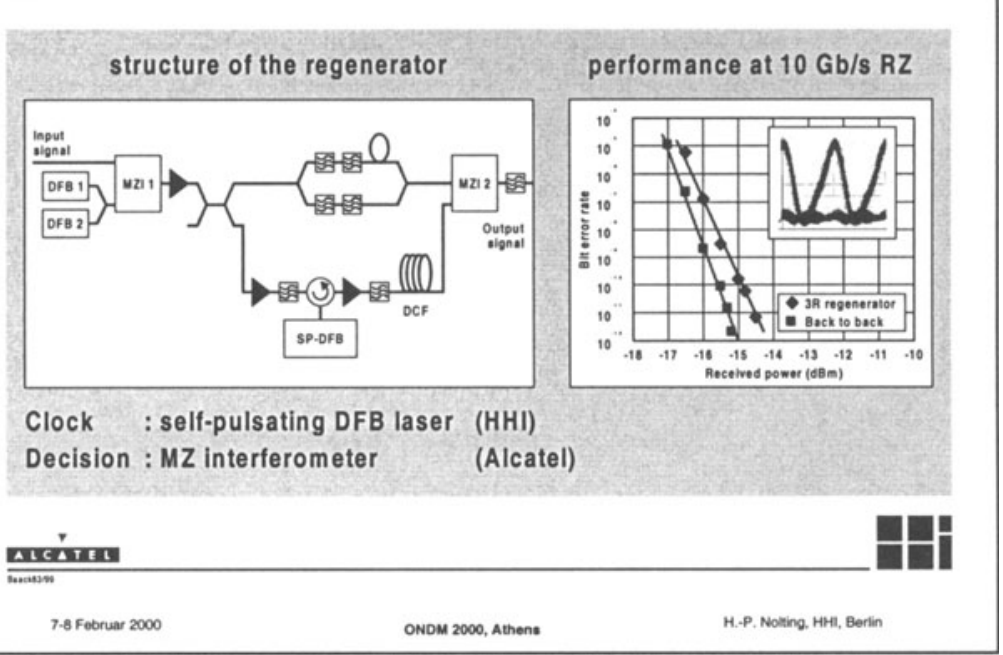




\section{OPTICAL PACKET SWITCHING}

Packet switching based on the Internet Protocol (IP) is a connectionless oriented traffic, basically invented for computer networks. The data are put into packets and sent randomly to the neighbours. All packets are built up of the data or payload and an additionally header, where the address is put in. Each node of the network has an address table of other neighbouring nodes.

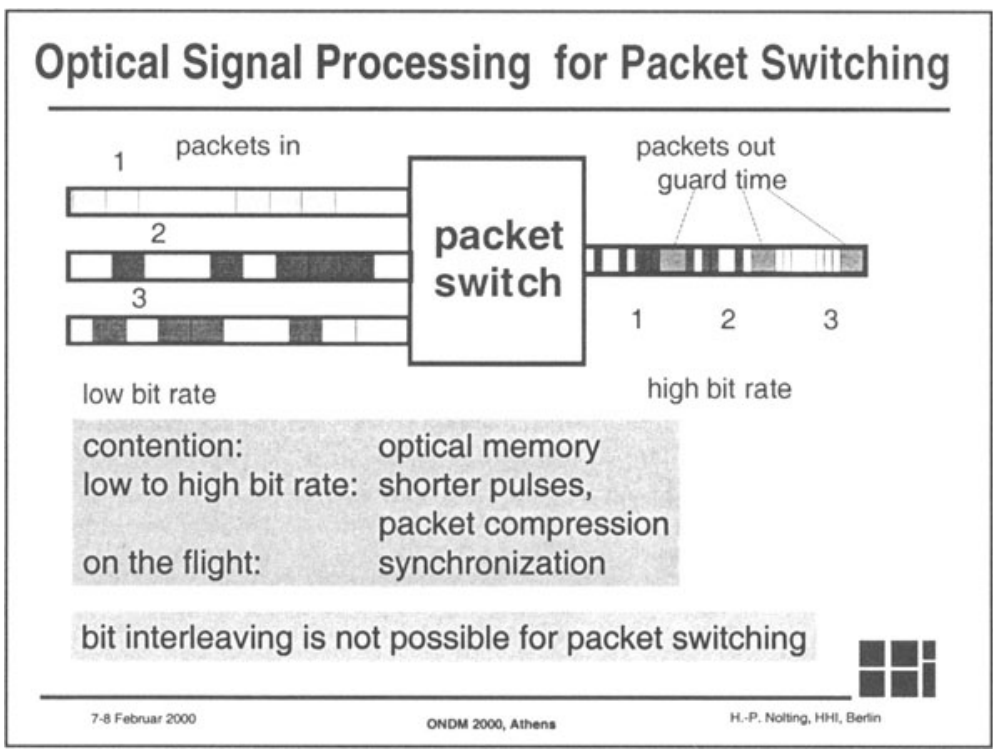

Based on this knowledge the packets are send to the next node, until it reaches its destination. Therefore the basic steps in a node are the following: storing a packet, identifying the address in the header, determining the output port of the node, writing a new header, sending the packet. All packets arriving in a node are queued until the processor has time to process the package. This signal processing can easily be done by today's computer, but it is a slow process, which increases the delay time for a packet propagating through the network.

Optical signal processing offers the chance for much faster processing time, especially if the packet is staying in the optical domain "on the flight", while the header is processed and a very fast switch is activated to send the packet to the next node. The non-linear MZ-Interferometer switch can be used as fast packet switch. 
One concept is label switching in IP, where the path through a domain is planned at the border nodes (blue) and the packet gets an additional label, which is processed by optical signal processing methods in the inner nodes (red) of the domain. The introducing of a label domain reduces the length of the address table and the processing time and includes some other advantages.

\section{Label Switching in IP over WDM}

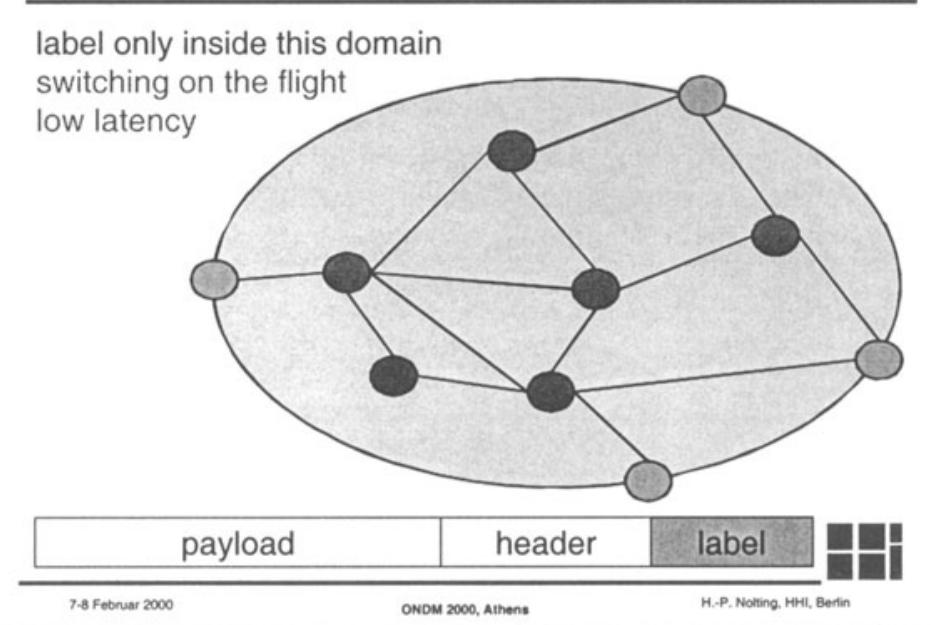

\subsection{Optical Memory}

In any case an optical memory is necessary for storing the packets during processing time. A well known solution is a fiber-ring memory with a 3Rregeneration to stabilise the signal shape. Again fast switching to open and shut the ring memory can be done by a MZI-switch. Synchronisation between two data streams is necessary. For this purpose switched delay lines have been investigated by several authors. 


\section{Terabit Router: switching on the flight}

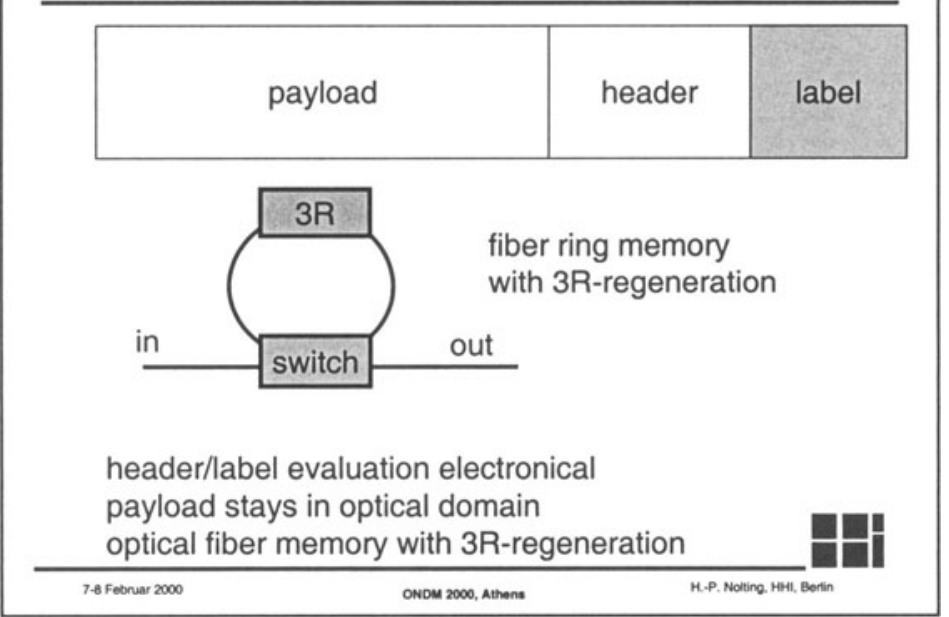

\subsection{Fast locking clock recovery for packet switching}

Packet switching is a burst mode of operation. Consecutive following packets are not synchronised as is usual in SDH. Therefore fast locking clock recovery circuits are needed. Here the selfpulsation multi-section DFB

\section{Fast Locking Clock Recovery}

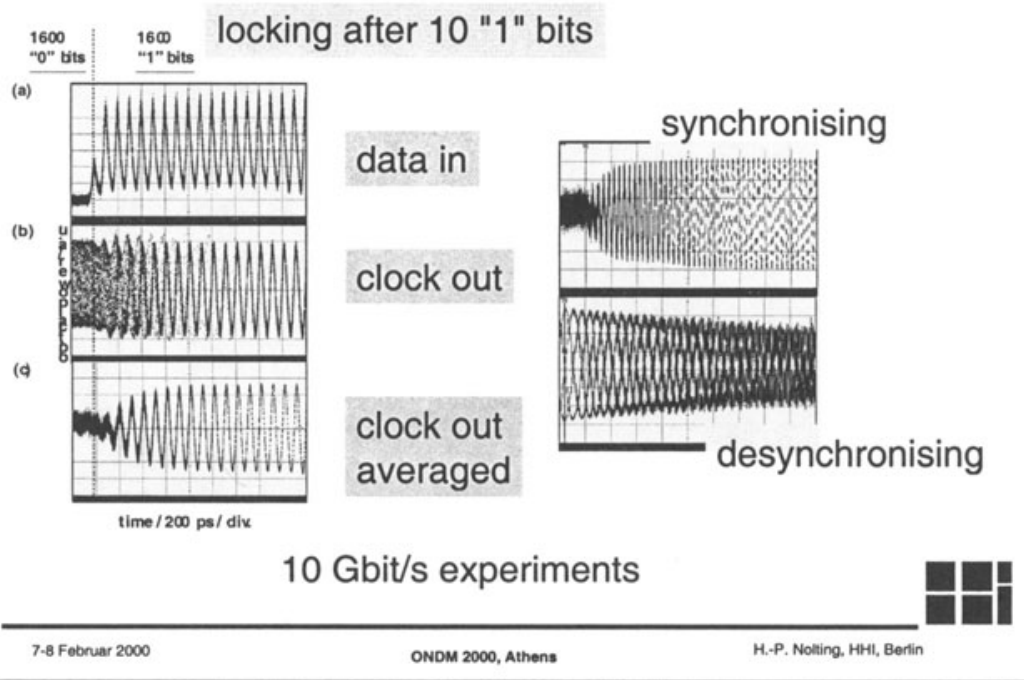


laser has its superior performance ${ }^{23}$. In experiments at $10 \mathrm{Gbit} / \mathrm{s}$ the synchronisation (locking) time has been investigated to a number of 10 " 1 " bits following a queue of 1600 " 0 " bits, representing the guard time of packets (see left side of figure "Fast Locking Clock Recovery"). This is a factor of 1000 shorter than is usual in today's electronic PLL circuits.

The number of " 0 " bits until the clock is desynchronised is in the order of a few hundred (see right side of figure). This "fast locking" function together with the "long memory" effect makes the selfpulsating DFB laser well suitable for all-optical packet switching applications. Together with fast optical gating devices a 3R-regenerator for packet switching can be built.

\subsection{Packet Compression and Decompression}

In OTDM transmission systems, the often used bit-interleaving technique for the multiplexing / demultiplexing can not be used any more for packets switching. Packets arriving at a lower bit rate at the node have to be compressed in time and bit shape and decompressed at the other end.

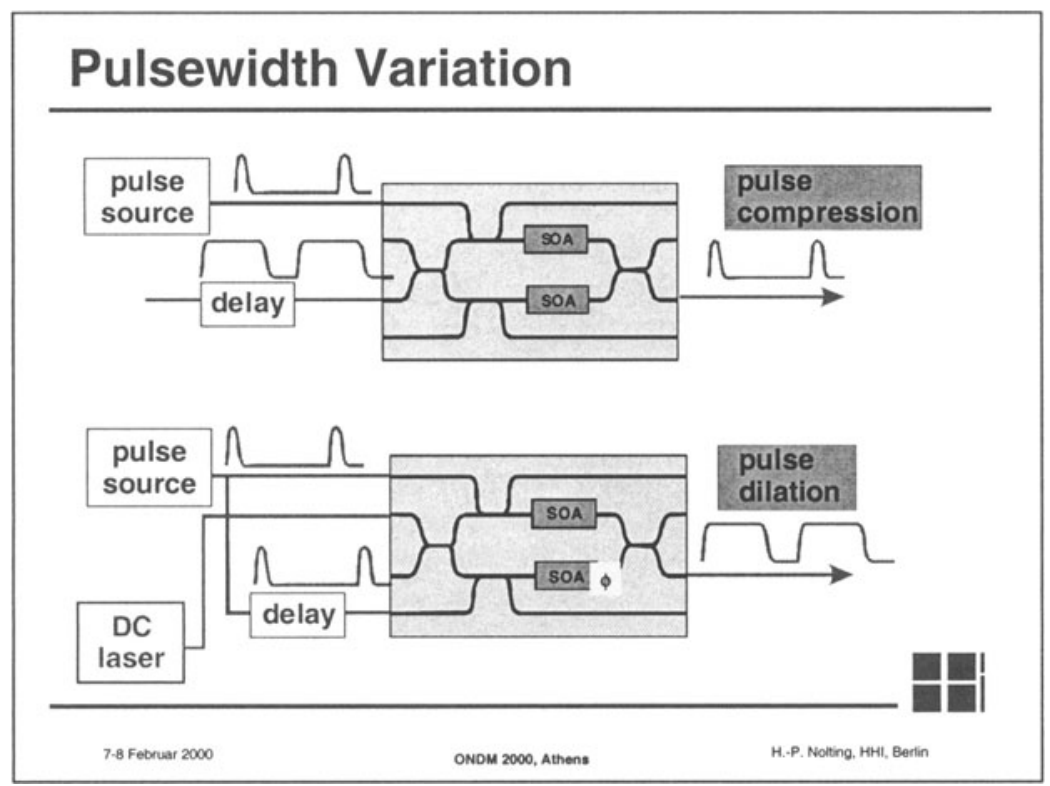

Non-linear MZ-Interferometer can be used for changing the width of signals. The MZ-interferometer acts as a logical and-function. A pulse source with short pulses synchronised to the data stream cuts a short pulse shape out of an incoming " 1 " bit. Thus the shape is compressed, but the time position is unchanged. 


\section{Pulse Dilation as Function of Phase}

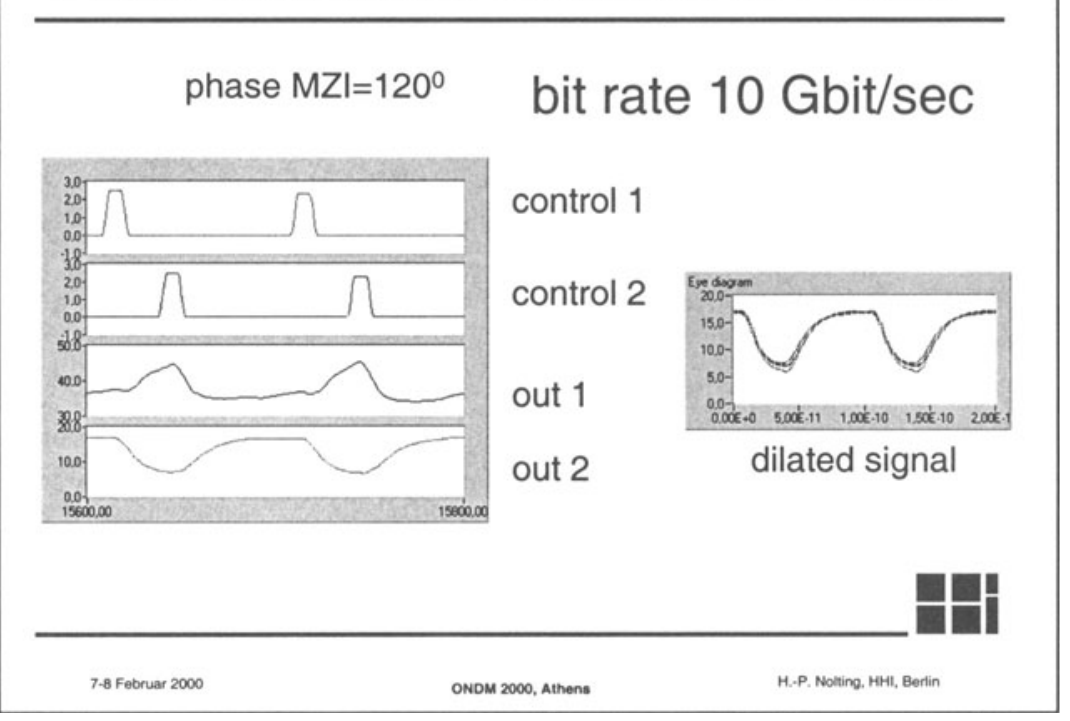

To increase the width of short incoming pulses they can be introduced at the control input of the MZ-interferometer in push-pull operation. The introduced delay determines the new pulse width. Here the coherent interaction of both pulses is used to make a flat output signal of the desired width. To control the shape an additional phase shifter is necessary. Some modeling results are shown.

This shaping of the pulses has to be done before and after the packet compression / decompression process. In the following we assume that the pulses are short enough for the higher bit rate.
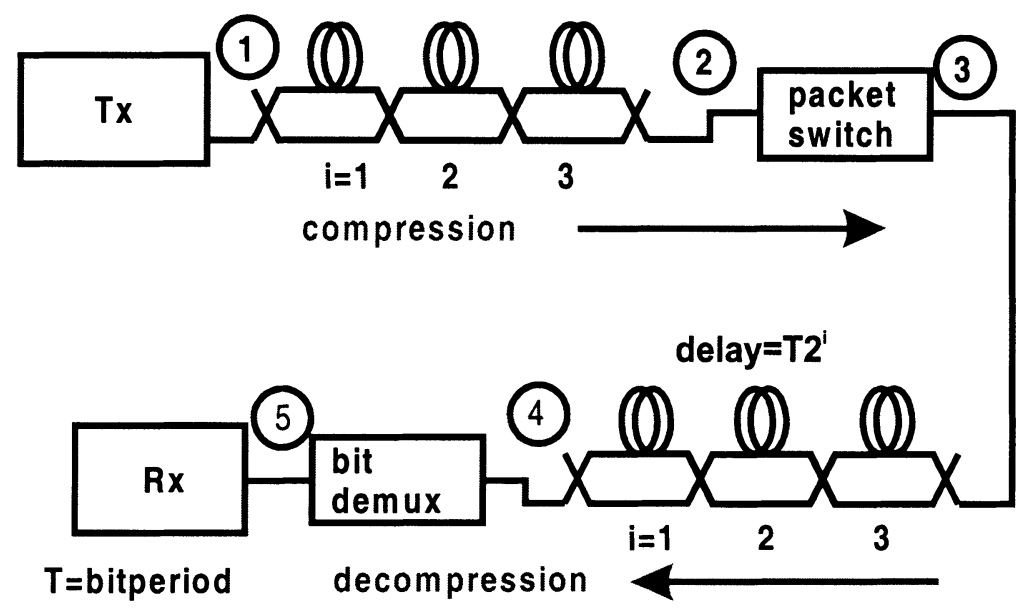
A method to compress and to uncompress a packet has been described by Prucnel $^{24}$. As is shown in the figure, a passive network of $n$ asymmetric Mach-Zehnder-Interferometer with a sequence of special dimensioned delays can be used to build up a compressed copy (at point 2) of the incoming packet (at point 1) of $2^{\mathrm{n}}$ bits. This packet has to be cut out (at point 3 ) by a fast optical switch from the other not usable copies of this device. The basic function of this device is shown in the following modelling results with a compression factor of 10 in the following figure. To identify correctly all bits in a packet, the incoming packet is modulated in the height of the amplitude (point 1). Please notice the very short pulses. At point 2 a sequence of copies is shown. Only one copy is the complete packet and has to be switched by the packet switch (3).

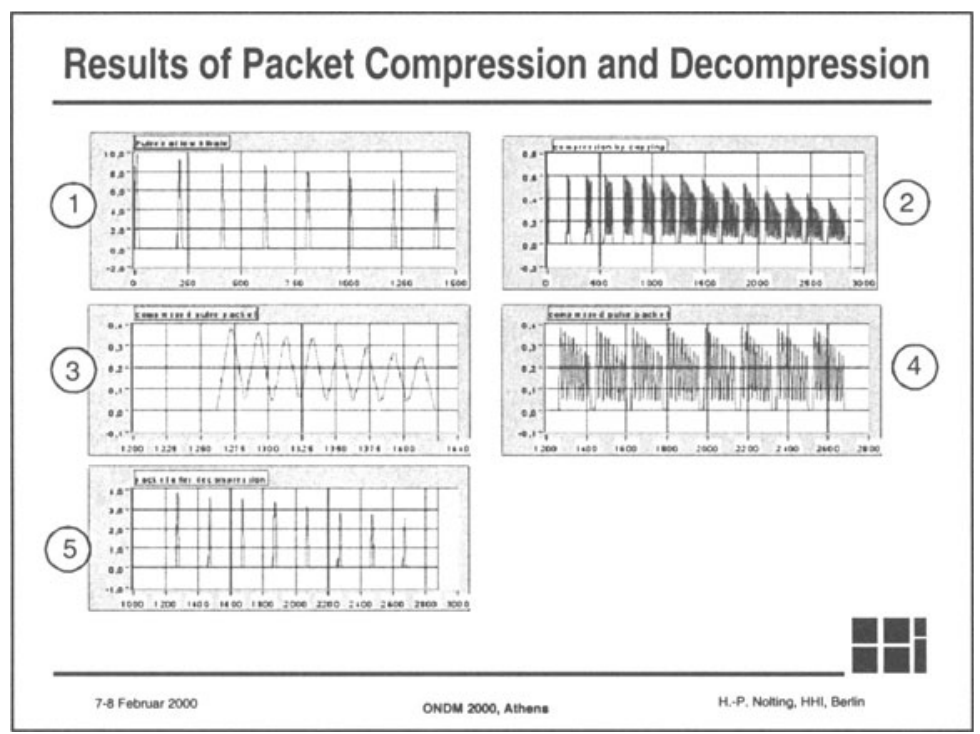

For the reverse process (decompression, dilation) the same sequence of passive MZIs can be used, as is shown in the lower part of both figures. At point 4 a sequence of copies of the original incoming short packet is shown. The bit demux has to switch out exactly one bit of the sequence at every period time $\mathrm{T}$. The resulting packet is shown at point 5 .

This concept has the advantage to compress and decompress, as example a packet of $2^{10}=1024$ bits with 10 MZIs in a sequence. The disadvantage is the fact, that the number of bits in a packet is limited to the quotient of the two bit rates. For a realistic scenario of 10 to $80 \mathrm{Gbit} / \mathrm{s}$ this is not acceptable. 
A much more realistic concept is to use a ring memory ${ }^{25}$ to collect all bits of a packet without any limitation of the packet length. This concept has the disadvantage that the bits are scrambled in a special order and therefore the compression and decompression has to be done in pairs of devices. But this is always the case in practice.

\section{Ring for packet de-/compression}

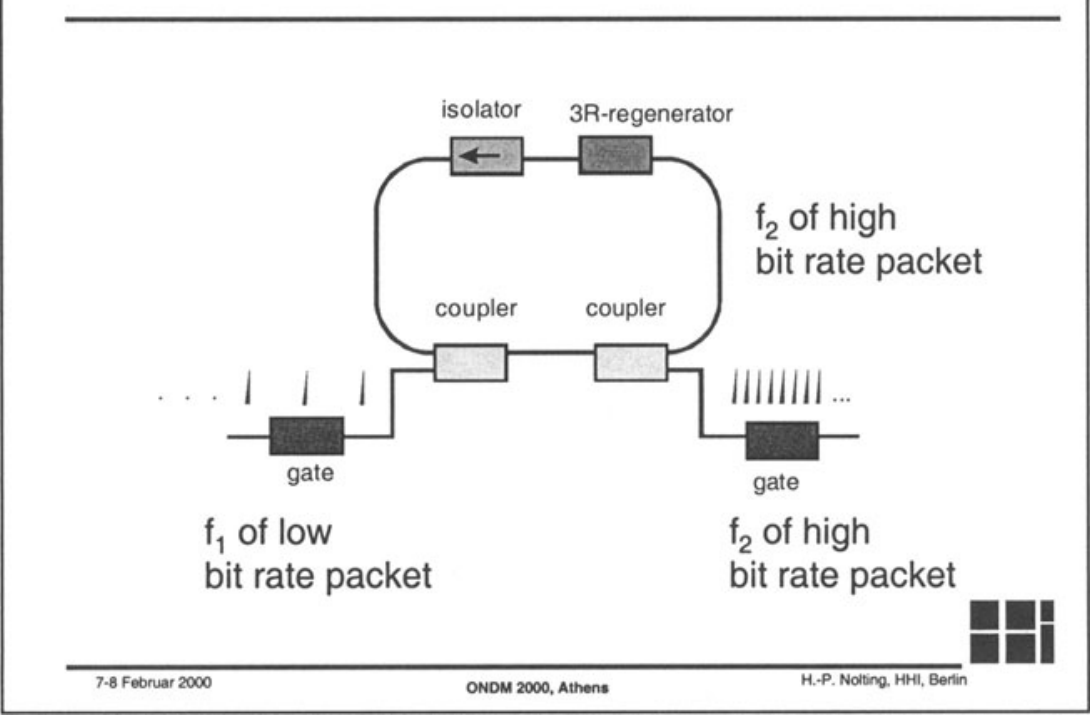

The scheme is based on the idea of self bit-interleaving (sometimes called rational harmonic mode locking ${ }^{25}$ ). Again we assume that the pulses are short enough for a bit-interleaving procedure, as is shown in both figures. To achieve rate conversion from low bit rate $f_{1}$ to high bit rate $f_{2}$ (as example take 10 to $40 \mathrm{Gbit} / \mathrm{s}$ ) the packet is divided into $\mathrm{n}$ slices of bit streams (one common color in figure) with the length of $m$ bits. Here $n$ is the ratio of both frequencies $\left(n=f_{2} / f_{1}\right)$. $m$ is the lowest number that fits $N \leq n * m-1$, where $N$ is the maximum number of bits in the whole packet. In the example shown in the figure we have less or equal than 31 bits and $n=4$ slices with a length of $\mathrm{m}=8$ time slots. Please notice, that the last slice has only $\mathrm{m}-1=7$ bits.

The ring length has to be adjusted to a length of exact $n^{*} m-1$ time slots at the higher bit rate $\mathrm{f}_{2}$. 
That means that the first slice of the low bit rate packet $(m=8$ bits in our example, yellow colored as is shown in the figure) enter the ring by the left coupler and start to propagate in the ring memory. The next slice of bits

\section{Packet Compression and Decompression per Ring}

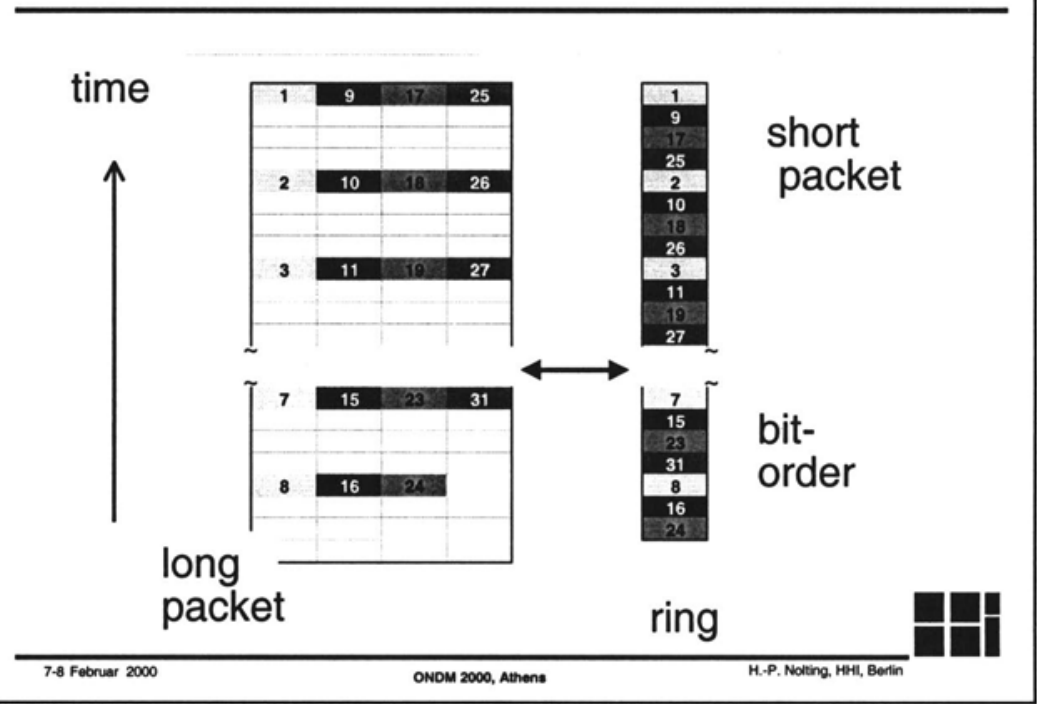

(number 9 to 14, green colored) meet a (short) time slot behind the bit numbers 1 to 8 . This behavior is described by the name self bit-interleaving process. The next slices (colored red and blue) are also slipped by one (short) time slot. All bits will find a well defined place in the compressed package. The gate at the right side controls the passing of the complete package.

Decompression can be done by inverting the self bit-interleaving process. The same ring memory architecture can be used. The gate at the right side has to open the output arm for a short time slot with the period of the low bit rate.

\section{SUMMARY}

The state of the art of the application of optical signal processing devices and subsystems in present OTDM-systems in the bit rate region 10 to 160 $\mathrm{Gbit} / \mathrm{s}$ have been highlighted. Some of the requirements and demands for future $1 \mathrm{Tbit} / \mathrm{s}$ systems and for future all optical packet switching at ultrahigh speed have been discussed. All optical signal processing methods and 
application will play a key role. New network concepts and the speed enhancement of semiconductor based materials or the development of new materials for all optical switching is a challenge.

\section{${ }^{1}$ Tunable mode locked laser as pulse source}

R.Ludwig, A. Ehrhardt Turn-key-ready wavelength-, repetition rate- and pulsewidth-tunable femtosecond hybrid modelocked semiconductor laser, Electronics Letters, Vol.31, 6th July 1995, No.14, pp. 1165-1167.

R. Ludwig, S. Diez, A. Ehrhardt, L. Küller, W. Pieper, H. G. Weber, A Tunable Femtosecond Modelocked Semiconductor Laser for Applications in OTDM-Systems, IEICE Trans. Electron., Vol. E81-C, No.2 (1998), pp. 140-145.

${ }^{2}$ C. Schmidt, E. Dietrich, S. Diet, H. J. Ehrke, U. Feiste, L. Küller, R. Ludwig, and H.-G. Weber, "Mode-locked semiconductor lasers and their applications for optical signal procesing", Conf. On Lasers and Electro-Optics (CLEO) Tech. Dig. P. 347-349, May 1999, paper CthA3

${ }^{3}$ H. G. Weber, D. Breuer20, U. Feiste, I. Koltchanov20, R. Ludwig and C. M. Weinert, HighSpeed Transmission over Standard Fiber, Proc. 25th Europ. Conf. Opt. Commun. 1, September 1999, pp. 196-199.

${ }^{4}$ W. Pieper, R. Ludwig, C. M. Weinert, B. Kuhlow, G. Przyrembel, M. Ferstl, E. Pawlowski, and H. G. Weber, „4-channel x $40 \mathrm{~Gb} / \mathrm{s}$ unrepeatered OTDM transmission over $100 \mathrm{~km}$ standard fiber“, IEEE Photon. Technol. Lett, vol. 10, pp. 451-453, 1998

5 Kazuro Kikuchi, "Ultra-high Speed Optimal Transmission System Design" The $6^{\text {th }}$ International Workshop on Femtosecond Technology, July 13-15. 1999, Makuhari Messe, Chiba, Japan

6 S.Diez, R.Ludwig, H.G.Weber: "All-optical switch for TDM and WDM/TDM systems demonstrated in a 640Gbit/s demultiplexing experiment", Electronics Letters, Vol.34, No.8, (1998) pp803-805

${ }^{7}$ J.-P. Elbers, C. Scheerer, A. Färbert, C. Glingener, A. Schöpflin, E. Gottwald, G. Fischer, “3,4 Tbit/s (80x40 Gbit/s) Bidirectional DWDM/ETDM Transmission", ECOC 99, September 26-30, 1999 Nice, France, Post-Deadline paper PD2-5, p 32-33

${ }^{8}$ B. Mikkelsen, G. Rayborn, R.-J. Essiambre, K. Dreyer, Y. Su, L. E. Nelson, J. E. Johnson, G. Shtengel, A. Bond, D. G. Moodie, A. E. Ellis, " $160 \mathrm{Gbit} / \mathrm{s}$ singel-channel transmission over $300 \mathrm{~km}$ nonzero-dispersion fiber with semiconductor based transmitter and demultiplexer", ECOC 99, Septembre 26-30, 1999, Nice, France, PD2-3, p32-33

9 S. Kawanishi, H. Takara, K. Uchiyama, I. Shake, K. Mori, "3 Tbit/s (160x19 ch) OTDM/WDM transmission experiment", Tech. Digest of OFC'99, PD1 (1999)

10 R.Ludwig, W.Pieper, H.G.Weber, D.Breuer, K.Petermann, F. Küppers, A.Mattheus, "Unrepeatered $40 \mathrm{Gbit} / \mathrm{s} \mathrm{RZ}$ single channel transmission over $150 \mathrm{~km}$ of standard fiber at 1.55 Mm”, Electronics Letters , Vol. 33, 2nd January 1997, No.1, pp. 76-77

11 U.Feiste, R.Ludwig, E.Dietrich, S.Diez, H.J.Ehrke, D.Razic, H.G.Weber, "40 Gbit/s transmission over $434 \mathrm{~km}$ Standard-Fiber Using Polarisation Independent Mid-Span Spectral Inversion”, Electronics Letters, Vol. 34, 15th October 1998, pp. 2044-2045

${ }^{12}$ W. Pieper, R. Ludwig, C. M. Weinert, B. Kuhlow, G. Przyrembel, M. Ferstl, E. Pawlowski, H. G. Weber, "4-channel x $40 \mathrm{Gbit} / \mathrm{s}$ unrepeatered OTDM-transmission over $100 \mathrm{~km}$ standard fiber", IEEE Photon. Technol. Lett., Vol. 10, No. 3, March 1998, pp. 451-453 
${ }^{13}$ R. Ludwig, U. Feiste, E. Dietrich, H.-G. Weber, D. Breuer, M. Martin, F. Küppers, "Experimental comparison of $40 \mathrm{Gbit} / \mathrm{s} \mathrm{RZ}$ and NRZ transmission over standard single mode fiber", Electr. Letters, (1999), in press

${ }^{14}$ U. Feiste, R. Ludwig, C. Schmidt, E. Dietrich, S. Diez, H.-J. Ehrke, E. Patzak, H.-G. Weber, T. Merker, " $80 \mathrm{Gbit} / \mathrm{s}$ transmission over $106 \mathrm{~km}$ standard fiber using optical phase conjugation in a Sagnac interferometer" IEEE Phot. Techn. Lett. Vol 11, (1999),pp 10631065

${ }^{15}$ Optical sampling

S.Diez, C.Schmidt, D.Hoffmann, C.Bornholdt, B.Sartorius, H.G.Weber, L.Jiang, A.Krotkus , Simultaneous Sampling of Optical Pulse Intensities and Wavelengths by Four-Wave Mixing in a Semiconductor Optical Amplifier, Applied Physics Letters, Volume 73, Issue 26, pp. 3821-3823, December 28, 1998.

${ }^{16}$ S.Diez, R.Ludwig, C.Schmidt, U.Feiste, H.G.Weber, "160 Gbit/s optical sampling by a novel ultra-broadband switch based on Four-Wave Mixing in a Semiconductor Optical Amplifier", Optical Fiber Communication Conference 1999, OFC '99, Technical Digest, post-deadline-paper PD38

${ }^{17}$ Conventional switch

E. Jahn, N. Agrawal, W. Pieper, H.-J. Ehrke, D. Franke, H. G. Weber, W. Fürst, "Monolithical integrated nonlinear sagnac interferometer and its application as a $20 \mathrm{Gbit} / \mathrm{s}$ all-optical demultiplexer", Integrated Photonics Research (IPR'96) (Boston,USA), April 1996, Techn. Dig. Vol. 6 paper ITuG3-1.

N. Agrawal, E. Jahn, W. Pieper, H.-J. Ehrke, "Semiconductor Laser Amplifier Based Integrated Interferometers for Add/Drop Multiplexing in OTDM Sytems", Fiber Integrated Optics, 10.-11. October 1996 (Berlin,Germany), SPIE Vol 2954, Proc. invited paper, pp. 166-177.

${ }^{18}$ Gain-Transparent switch

S.Diez, R.Ludwig, H.G.Weber:, "All-optical switch for TDM and WDM/TDM systems demonstrated in a 640Gbit/s demultiplexing experiment", Electronics Letters, Vol.34, No.8, (1998) pp803-805

S.Diez, R.Ludwig, H.G.Weber , "Gain-Transparent SOA-Switch for High Bitrate Add/Drop Multiplexing”, IEEE Photon. Technol. Lett., vol. 11, no. 1, pp. 60-62, 1999.

R. Ludwig, S. Diez, H. G. Weber:, "A novel all-optical switch for demultiplexing in OTDMsystems demonstrated in a $640 \mathrm{Gbit} / \mathrm{s}$ WDM/TDM experiment", Optical Fiber Communication Conference 1998, OFC '98, postdeadline paper PD22 (1998)

${ }^{19} \mathrm{H}$. Kobayashi, R. Takahashi, Y. Matsuoka and H. Iwamura, "1 Tbit/s demultiplexing using low temperature grown InGaAs/InAlAs multiple quantum wells", Elect. Letters, Vol. 34, No, 9, p. 908-910

${ }^{20}$ Selfpulsating laser as clock recovery

B. Sartorius, C. Bornholdt, O. Brox, H.J. Ehrke, D. Hoffmann, R. Ludwig, and M. Möhrle:

"System performance of an all-optical clock recovery module" ECOC'98, Madrid, Conf. Proc. pp.505-506, 1998.

A. Buxens, A.T. Clausen, H.N. Poulsen, K.S. Jepsen, K.E. Stubkjaer, C. Bornholdt, O. Brox, and B. Sartorius: 40 to $10 \mathrm{~Gb} / \mathrm{s}$ demultiplexing using a self-pulsating DFB laser for clock recovery, ECOC'98, Madrid, Conf. Proc. pp.507-508, 1998.

B. Sartorius, C. Bornholdt, O. Brox, H.J. Ehrke, D. Hoffmann, R. Ludwig, and M. Möhrle:

"All-Optical Clock Recovery Module Based on a Self-Pulsating DFB Laser", Electron. Lett., 34, pp.1664-1665, 1998.

B. Sartorius, C. Bornholdt, O. Brox, M. Möhrle, P. Brindel, O. Leclerc and E. Desurvire :

"Analysis and Compression of Pulses Emitted from an All-Optical Clock Recovery Module" 
Electron. Lett. 34, pp 2344-2345, 1998

${ }^{21}$ B. Sartorius, C. Bornholdt, O. Brox, H.J. Ehrke, D. Hoffmann, R. Ludwig, and M. Möhrle:"Bit-rate flexible all-optical clock recovery", OFC'99, San Diego, USA, paper FB1

${ }^{22}$ C. Bornholdt, B. Sartorius, M. Möhrle, "All-Optimal Clock Recovery at $40 \mathrm{Gbit} / \mathrm{s}$ ", ECOC 99, September 26-30, 1999, Nice France, Post-Deadline Paper PD3-5, p 54-55

${ }^{23}$ S. Bauer, C. Bornholdt, O. Brox, D. Hoffmann, M. Möhrle, G. Sahin, B.Sartorius, S. Schelhase, B. Lavigne, and D. Chiaroni, " Ultrafast Locking Optical Clock for IP Packet Switching Applications", paper TuF5 at OFC 2000, Baltimore, USA

${ }^{24}$ P. P. Prucnal, S. W. Seo, Applied Optics, 35, pp. 3815-3818 (1996)

P. Toliver, K.-Li Deng, I. Glesk, P. R. Prucenal, "Simultaneos Optical Compression and Decompression of $100 \mathrm{Gbit} / \mathrm{s}$ OTDM Packets Using a Single TOAD and a Bi-directional Optical Delay Line Lattice, Photonics in Switching, Technical Digest, July 21-23. 1999. Santa Barbara, Ca, USA, paper PWB2-1/35

25 Chongjin Xie, Peida Ye, "A novel scheme of optical packet-compression and decompression for all-optical packet switching networks", ECOC 99, 26-30 September 1999, Nice, France, p I-258-259 